\title{
Azithromycin has enhanced effects on lung fibroblasts from idiopathic pulmonary fibrosis (IPF) patients compared to controls
}

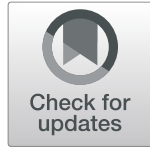

Kristina Krempaska ${ }^{1,2,3}$, Sandra Barnowski ${ }^{1,2}$, Jacopo Gavini ${ }^{4}$, Nina Hobi ${ }^{5,6}$, Simone Ebener ${ }^{1,2}$, Cedric Simillion ${ }^{2,7}$, Andrea Stokes ${ }^{1,2}$, Ronja Schliep ${ }^{8}$, Lars Knudsen ${ }^{8,9}$, Thomas K. Geiser ${ }^{1,2}$ and Manuela Funke-Chambour ${ }^{1,2^{*}}$

\begin{abstract}
Background: Idiopathic pulmonary fibrosis (IPF) is a chronic fatal lung disease without a cure and new drug strategies are urgently needed. Differences in behavior between diseased and healthy cells are well known and drug response can be different between cells isolated from IPF patients and controls. The macrolide Azithromycin (AZT) has anti-inflammatory and immunomodulatory properties. Recently anti-fibrotic effects have been described. However, the anti-fibrotic effects on primary IPF-fibroblasts (FB) directly compared to control-FB are unknown. We hypothesized that IPF-FB react differently to AZT in terms of anti-fibrotic effects.
\end{abstract}

Methods: Primary normal human lung and IPF-FB were exposed to TGF- $\beta(5 \mathrm{ng} / \mathrm{ml})$, Azithromycin $(50 \mu \mathrm{M})$ alone or in combination prior to gene expression analysis. Pro-collagen la1 secretion was assessed by ELISA and protein expression by western blot (aSMA, Fibronectin, ATP6V1B2, LC3 AB (II/I), p62, BCl-xL). Microarray analysis was performed to screen involved genes and pathways after Azithromycin treatment in control-FB. Apoptosis and intraluminal lysosomal pH were analyzed by flow cytometry.

Results: AZT significantly reduced collagen secretion in TGF- $\beta$ treated IPF-FB compared to TGF- $\beta$ treatment alone, but not in control-FB. Pro-fibrotic gene expression was similarly reduced after AZT treatment in IPF and control-FB. P62 and LC3II/I western blot revealed impaired autophagic flux after AZT in both control and IPF-FB with significant increase of LC3II/I after AZT in control and IPF-FB, indicating enhanced autophagy inhibition. Early apoptosis was significantly higher in TGF- $\beta$ treated IPF-FB compared to controls after AZT. Microarray analysis of control-FB treated with AZT revealed impaired lysosomal pathways. The ATPase and lysosomal pH regulator ATP6VOD2 was significantly less increased after additional AZT in IPF-FB compared to controls. Lysosomal function was impaired in both IPF and control FB, but pH was significantly more increased in TGF- $\beta$ treated IPF-FB.

Conclusion: We report different treatment responses after AZT with enhanced anti-fibrotic and pro-apoptotic effects in IPF compared to control-FB. Possibly impaired lysosomal function contributes towards these effects. In summary, different baseline cell phenotype and behavior of IPF and control cells contribute to enhanced anti-fibrotic and proapoptotic effects in IPF-FB after AZT treatment and strengthen its role as a new potential anti-fibrotic compound, that should further be evaluated in clinical studies.

Keywords: Idiopathic pulmonary fibrosis (IPF), Anti-fibrotic drug, Azithromycin, Lysosomes, Apoptosis

\footnotetext{
* Correspondence: manuela.funke-chambour@insel.ch

${ }^{1}$ Department of Pulmonary Medicine, Inselspital, Bern University Hospital,

University of Bern, $\mathrm{CH}-3010$ Bern, Switzerland

2Department for BioMedical Research, University of Bern, Bern, Switzerland

Full list of author information is available at the end of the article
} 


\section{Background}

Idiopathic pulmonary fibrosis (IPF) is a devastating progressive lung disease causing dyspnea and cough, which ultimately leads to respiratory failure [1]. IPF affects mainly male patients over 60 years and genetic associations have been described [2]. The mortality is comparable to severe cancer disease with a median survival of $2-3$ years [2]. New drugs slow down disease progression and may prolong survival $[3,4]$. Nevertheless, today no cure is available and in advanced disease eligible patients ultimately require lung transplantation, or else they succumb to their disease [2]. New and improved drug strategies are thus urgently needed.

To develop or apply existing drugs for new use, the underlying pathomechanisms need to be fully understood. The pathogenesis of IPF remains still unclear. Presently it is believed that injury of the alveolar epithelial lining followed by aberrant wound healing is the initiating event for IPF development [5]. Although epithelial cells are thought to initiate fibrosis, differentiated fibroblasts, socalled myofibroblasts, are the main mesenchymal actor cells in fibrogenesis. They originate from local fibroblasts or other precursor cells and produce extracellular matrix leading to increased lung stiffness and loss of respiratory function [6]. The differentiation into myofibroblasts is driven by pro-fibrotic mediators, including cytokines such as transforming growth factor- $\beta$ (TGF- $\beta$ ) [7], which is considered the main pro-fibrotic cytokine [8].

Fibroblasts isolated from IPF patients show particular properties such as insufficient autophagy $[9,10]$. Impaired autophagy in IPF lungs may contribute to fibrogenesis and promote fibroblast activation and extracellular matrix production [11]. Autophagy can be modulated by drugs. Recently, a study has shown that autophagy is reduced after Azithromycin (AZT) treatment and affects fibrosis [12]. Autophagy inhibition in lung fibroblasts induced proteasomal degradation of pro-fibrotic NOX4 [13]. NOX4 reduction then decreased myofibroblast differentiation in normal human lung fibroblasts [12]. In vivo, AZT has anti-fibrotic effects in the bleomycin rodent model for lung fibrosis [14]. In clinical routine AZT is used as an antibiotic. AZT is a potent macrolide antibiotic known to inhibit bacterial protein synthesis by binding to the $50 \mathrm{~S}$ large ribosomal unit [15]. AZT shares the same mechanism of antibacterial action as other macrolides, but it has been found to accumulate more effectively in phagocytes where it can efficiently be delivered to the site of infection $[15,16]$. AZT was also described to accumulate in other cell types such as epithelial cells and fibroblasts [15]. Long-term use of AZT in COPD, asthma and cystic fibrosis has been reported with improved clinical outcomes such as reduced exacerbations and cough [17-19]. The exact mechanisms remain unknown, but antiinflammatory effects on macrophages and neutrophils might be involved [20]. Inflammation also contributes to acute exacerbations in IPF [21]. In recent retrospective clinical observations, AZT reduced mortality in acute exacerbations and hospitalization rates of IPF patients $[22,23]$. In addition to antimicrobial effects, AZT might act on inflammation and thus reduce severity of acute exacerbation. Despite recent findings of a positive role of AZT in lung fibrosis, the role and precise mechanism of its effects on exacerbation and lung fibrosis remain unclear. Also, cells might act differently when derived from patients or healthy controls [24].

In our study, we tested the anti-fibrotic properties of AZT. We hypothesized that IPF fibroblasts react differently to AZT treatment than normal fibroblasts. We thus investigated whether AZT has enhanced antifibrotic effects on IPF fibroblasts compared to control fibroblasts. We further investigated the underlying mechanisms of divergent responses from control and IPF fibroblasts specifically for cell death, autophagy as well as lysosomal function.

\section{Methods}

Primary fibroblasts from IPF patients and controls

We obtained control fibroblasts from healthy lung tissue from patients undergoing tumor resection at the University Hospital of Bern, Switzerland. All study participants provided their informed written consent, as approved by the local Ethics Committee, Bern, Switzerland (KEK-BE: 042/2015). We received additional lung fibroblasts from control and IPF patients from diagnostic biopsies and/or lung explants isolated and cultured as previously described and kindly provided by Prof. Crestani, Paris, France [25].

\section{Material, cell culture and antibodies}

We used Ham's F-12 K (Gibco, Waltham, MA) media supplemented with 10\% Fetal Bovine Serum (FBS) (Gibco, Waltham, MA) and 1\% Penicillin Streptomycin (Gibco, Waltham, MA) for cell culture. We treated cells for $24 \mathrm{~h}$ as follows: 1 . Starvation media control including the respective vehicle control (Media without FBS plus $50 \mu \mathrm{M}$ Ethanol as the dissolvent for AZT), 2. Azithromycin $(50 \mu \mathrm{M}$, dissolved in Ethanol) (Sigma-Aldrich, St. Louis, MO) 3. TGF- $\beta$ ( $5 \mathrm{ng} / \mathrm{ml}$ plus $50 \mu \mathrm{M}$ Ethanol) (R\&D Systems, Minneapolis, MN) or 4. Azithromycin $(50 \mu \mathrm{M}$, dissolved in Ethanol) with simultaneous TGF- $\beta$ stimulation. Each condition was tested and repeated in three independently performed experiments. The following antibodies were used for immunofluorescent staining: primary monoclonal antibody mouse anti- $\alpha \mathrm{SMA}$ (Sigma-Aldrich, St. Louis, MO), monoclonal antivinculin-FITC (Sigma-Aldrich, St. Louis, MO) and secondary antibody Alexa Fluor 488 goat anti-rabbit (Life 
Technologies, Carlsbad, CA). Lysotracker Green DND-26 (Life Technologies, Carlsbad, CA) dye for life lysosomal staining. Following western blot antibodies were used: mouse anti- $\alpha$ SMA (Sigma-Aldrich, St. Louis, MO), rabbit anti-Fibronectin (FN) (Abcam, Cambridge, UK), rabbit anti-ATP6V1B2, rabbit anti-LC3 AB (II/I), monoclonal Smad3 and pSmad3 rabbit antibodies (Cell Signaling Technology, Danvers, MA), rabbit anti-p62 (Sigma-Aldrich, St. Louis, MO) and rabbit anti-Bcl-xL antibodies (Cell Signaling Technology, Danvers, MA). Infrared IRDye (680 or $800 \mathrm{CW}$ ) secondary antibodies (LI-COR Biosciences, Lincoln, NE).

\section{Isolation of primary control human lung fibroblasts}

We isolated fibroblasts from human lung tissue, as described previously [26]. Cell culture passages between 3 and 8 were used for experiments. We treated our samples for $1 \mathrm{~h}, 24 \mathrm{~h}$ or $48 \mathrm{~h}$ as described.

\section{Isolation of total RNA and RT-qPCR}

We used Nucleospin RNA kit (Macherey-Nagel, Switzerland) to isolate RNA according to the manufacturer's instructions. We used the $\Delta \Delta \mathrm{Ct}$ method to calculate mRNA expression levels. RNA copy numbers were normalized to $\beta 2$ microglobulin $(\beta 2 \mathrm{~m})$ expression as previously described [26]. Human forward and reverse primers are listed in Table 1. Each condition was repeated three times and in independently performed experiments.

\section{Immunofluorescent staining and microscopy}

We seeded control and IPF fibroblasts on IBIDI ${ }^{\circledR}$ chamber slides (Thermo Fischer Scientific, Waltham, MA). The cells were grown until $80 \%$ confluency was reached and kept in resting media for $24 \mathrm{~h}$. Afterwards, the cells were fixated and incubated with the respective primary and secondary antibodies. To identify lysosomes, we used Lysotracker ${ }^{\circledR}$ Green dye (Life Technologies, Carlsbad,
CA) life staining. Pictures were taken with Leica DMI4000 B fluorescence microscope using the 20x and 63x magnification (Plan-Apochromat 63x/0.7 Oil).

\section{Western blot}

We treated control and IPF fibroblasts with TGF- $\beta$ (5 $\mathrm{ng} / \mathrm{ml})$ and/or AZT $(50 \mu \mathrm{M})$ for $48 \mathrm{~h}$ for the analysis of aSMA, Fibronectin, ATP6V1B2, LC3 AB (II/I) and p62. Incubation time for Bcl-xL analysis was $24 \mathrm{~h}$ and $1 \mathrm{~h}$ to evaluate SMAD3 phosphorylation. Cells were harvested using Pierce IP Lysis Buffer (Thermo Fischer Scientific, Waltham, MA) according to the manufacturer's instructions. We normalized infrared fluorescent signals to internal control monoclonal $\beta$-actin mouse antibody (LICOR Biosciences, Lincoln, NE) and quantified their intensities as previously described [26].

\section{Apoptosis and cell death measurements}

Fibroblasts were grown to $80 \%$ confluency on 6-well plates preceding treatment. We used Annexin V (A) and Propidium Iodide (PI) (Biolegend, San Diego, CA) dyes according to manufacturer's instructions for flow cytometry analysis. To evaluate cytotoxicity of Azithromycin in control and IPF fibroblasts, we measured the release of lactate dehydrogenase (LDH) in cell supernatants after $24 \mathrm{~h}$ of treatment by a colorimetric assay according to the manufacturer's instructions. We measured the optical densitiy at $540 \mathrm{~nm}$ using an Infinite M1000 PRO microplate reader (TECAN, Männerdorf, Switzerland) as previously described [27]. Bcl-xL was measured by western blot as described above.

\section{Lysosomal pH measurements}

We determined lysosomal $\mathrm{pH}$ using FITC-Dextran loaded fibroblasts following a previously published protocol [28]. We seeded control and IPF fibroblasts in 6-well plates with a FITC-Dextran loaded medium solution $(0.1 \mathrm{mg} / \mathrm{ml}$ - FD40S - Sigma-Aldrich) for 48 to 72

Table 1 Primer sequences for RT-qPCR

\begin{tabular}{lll}
\hline Gene of interest & Forward primer & Reverse primer \\
\hline B2microglobulin (B2M) & CTCCGTGGCCTTAGCTGTG & TTGGAGTACGCTGGATAGCCT \\
a-smooth muscle actin (aSMA) & CAGGGCTGTTTCCCATCCATGTCTATCGGGTACTTC \\
Collagen 1A1 (COL) & CCAGAAGAACTGGTACATCAGCA & CGCCATACTCGAACTGGGAAT \\
Fibronectin (FN) & TAAAGGACTGGCATTCACTGA & GTGCAAGGCAACCACACTGAC \\
ATP6V1B2 & TAGTTCAGGTATTTGAAGGGAC & GGTGTTCGGAGAATATCCC \\
ATP6V0D2 & TCTCACCTATATGACGTGCAGT & GGTGGCACTTCCCCAGAATT \\
RAB7B & GGCCAGCATCCTCTCCAAGATTATC & GATGCAGCCATCGGAGCCCTTGT \\
TMEM55b & GGTTATCTGTGGACATTGCA & ATAGATGACACTTTCCTGCAG \\
Cathepsin B (CTSB) & TGACGAGGATGACAGGGAACTA \\
Cathepsin C (CTSC) & TTCTTGCGACTCTTGGGACTTC \\
Cathepsin D (CTSD) & CCTATCTTGACCTGCTGGG & CATTCTTCACGTAGGTGCTGGA \\
\hline
\end{tabular}


$\mathrm{h}$ prior to treatment. FITC-Dextran medium was then removed by aspiration and fresh cell culture medium was added with the respective treatments for a $24 \mathrm{~h}$ incubation time. We determined the lysosomal $\mathrm{pH}$ by flow cytometry using a standard curve scale $(\mathrm{pH}$ scale from 4 to 6) which was compared to the treated samples.

\section{Elisa}

We used a monoclonal ELISA kit (R\&D Systems, Minneapolis, MN) according to the manufacturer's instructions to determine concentrations for pro-collagen I $\alpha 1$ (pro-Col1A1).

\section{Transmission electron microscopy}

AZT-induced vacuolar structures of control and IPF fibroblasts were analyzed in Hannover, Germany at the Institute for Anatomy by transmission electron microscopy. The preparation for electron microscopic evaluation was performed according to established methods [29]. In brief, cell pellets were fixed by immersion using a fixation mixture of $1.5 \%$ PFA, $1.5 \%$ GA in $0.15 \mathrm{M}$ HEPES buffer. Afterwards, fixed cells were embedded in epoxy resin $\left(E^{\circ}{ }^{\circ}\right)$ and ultrathin sections of a thickness of $60 \mathrm{~nm}$ were cut. Sections were investigated using a transmission electron microscope (Morgagni, Fei, Eindhoven, The Netherlands).

\section{GeneChip microarray assay and data analysis}

We performed microarray analysis to screen involved pathways after AZT treatment in control lung fibroblasts. Microarray analysis was performed on isolated total RNA samples. RNA isolation is described above and concentration was determined spectrophotometrically using Nanodrop (NanoDrop 2000). Sample preparation for microarray hybridization was carried out as described in the Affymetrix GeneChip WT PLUS Reagent Kit User Manual (Affymetrix, Inc., Santa Clara, CA, USA). In brief, $100 \mathrm{ng}$ (50 ng of sample no. 09) of total RNA was used to generate double-stranded cDNA. $15 \mu \mathrm{g}$ of subsequently synthesized cRNA was purified and reverse transcribed into sense-strand (ss) cDNA, whereat unnatural dUTP residues were incorporated. Purified ss cDNA was fragmented using a combination of uracil DNA glycosylase (UDG) and apurinic/apyrimidinic endonuclease 1 (APE 1) followed by a terminal labeling with biotin. 3,8 $\mu$ g fragmented and labeled ss cDNA were hybridized to Affymetrix Clariom $\mathrm{S}$ human arrays for $16 \mathrm{~h}$ at $45^{\circ} \mathrm{C}$ in a GeneChip hybridization oven 640. Hybridized arrays were washed and stained in an Affymetrix Fluidics Station FS450, and the fluorescent signals were measured with an Affymetrix GeneChip Scanner 3000 7G. Fluidics and scan functions were controlled by Affymetrix GeneChip Command Console v4.1.3 software. Sample processing was performed at an
Affymetrix Service Provider and Core Facility, "KFB Center of Excellence for Fluorescent Bioanalytics" (Regensburg, Germany; www.kfb-regensburg.de). RNA microarray data from control lung fibroblasts treated with Azithromycin versus non-treated can be downloaded from the ArrayExpress database at EMBL-EBI (www.ebi.ac.uk/arrayexpress) under accession number E-MTAB-8488. Summarized probe set signals in $\log 2$ scale were calculated by using the GCCN-SST-RMA algorithm with the Affymetrix GeneChip Expression Console v1.4 Software. After exporting into Microsoft Excel, average signal values, comparison fold changes and significance $P$ values were calculated. Probe sets with a fold change above 2.0 fold and a student's T-test $P$ value $<0.05$ were considered statistically significant. Differentially expressed genes were further analyzed and evaluated in the Department of Biostatistics, Bern, Switzerland (Cedric Simillion). Microarray data were analyzed using custom CDFs and data was normalized and log-transformed using the RMA method [30, 31]. Differential gene expression was calculated using the limma $R$ package [32]. Pathway analysis was conducted with the SetRank package [33].

\section{Statistical analysis}

Comparisons between control and IPF fibroblasts under different treatment conditions were tested by ONE-way ANOVA followed by Bonferroni's multiple comparison post test for unequal sample sizes and Tukey's post test for equal sample sizes using GraphPad Prism 7 (GraphPad Software Inc., La Jolla, CA). Student's T-test was used to compare the mean $( \pm \mathrm{SE})$ between only two treatment conditions. $P<0.05$ was considered statistically significant.

\section{Results}

AZT has enhanced anti-fibrotic effects on extracellular matrix formation, cytokine production and myofibroblast differentiation in IPF fibroblasts compared to controls

We investigated whether Azithromycin (AZT) differently affects the fibrotic response in lung fibroblasts from normal human lung fibroblasts and IPF fibroblasts (referred to as controls and IPF-FB). We found that gene expression of the pro-fibrotic markers collagen I 1 (Col1A1) and fibronectin (FN) were expectedly increased after TGF- $\beta$ stimulation over $24 \mathrm{~h}$ in both cell types (Fig. 1a and $\mathrm{b})$. Additional AZT treatment significantly reduced Col1A1 gene expression in control and in IPF fibroblasts (Fig. 1a). The pro-fibrotic marker FN was not significantly reduced neither in control nor in IPF fibroblasts (Fig. 1b) when combined data from cells from different individuals were analyzed. However, when the individual control and IPF fibroblasts were analyzed, FN was also significantly reduced after AZT and TGF- $\beta$ treatment (Additional file.1: Figure S1A and S1B). This statistical 


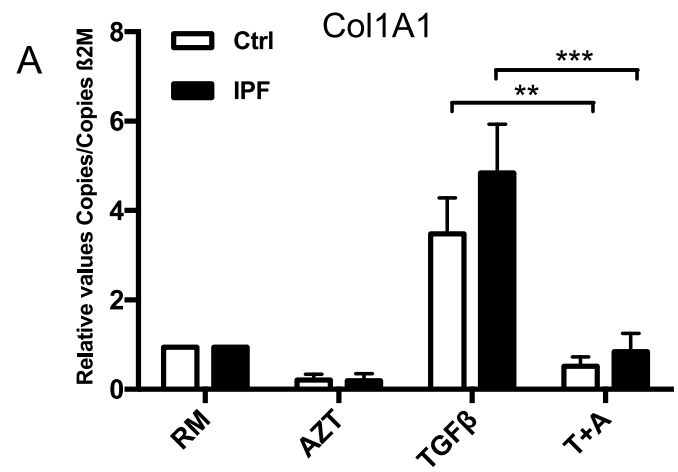

C

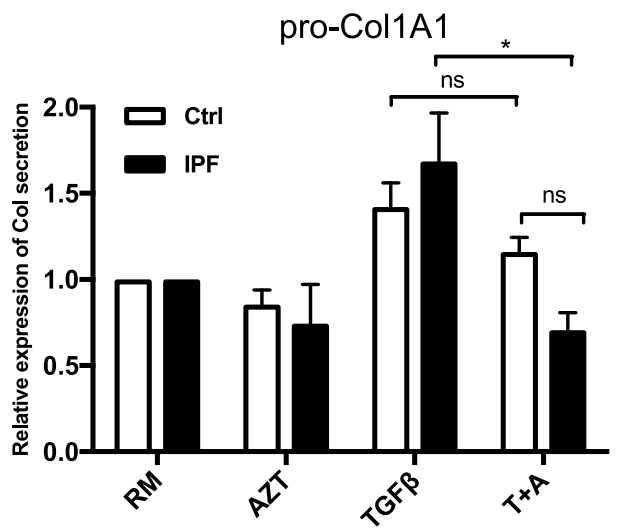

$E$

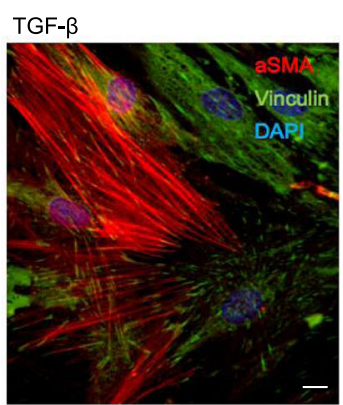

B

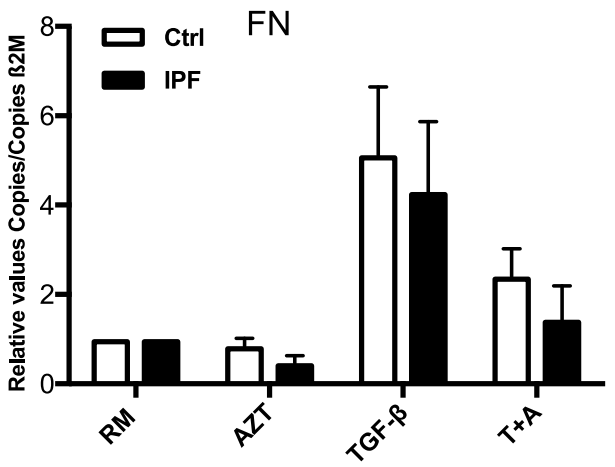

D
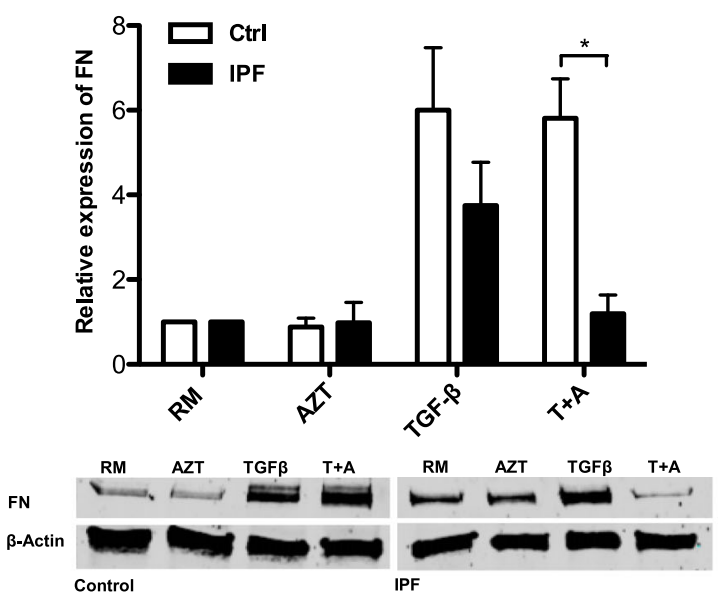

F

$\alpha \mathrm{SMA}$
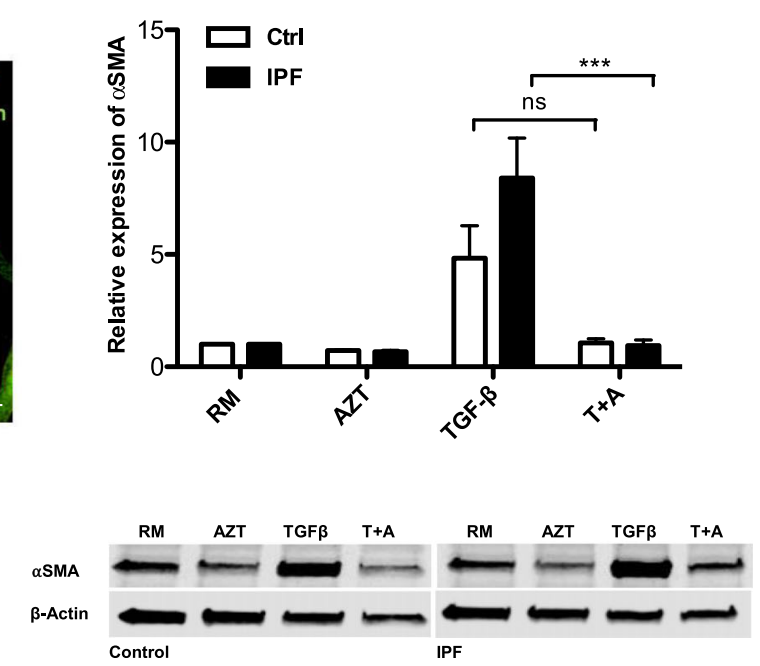

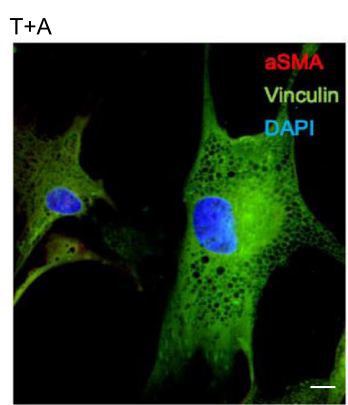


(See figure on previous page.)

Fig. 1 Anti-fibrotic effects of AZT in control and IPF fibroblasts. Isolated control human lung fibroblasts $(n=5)$ and IPF fibroblasts $(n=5)$ were treated with resting media (RM) for $24 \mathrm{~h}, 50 \mu \mathrm{M}$ AZT, $5 \mathrm{ng} / \mathrm{ml}$ TGF- $\beta$ or co-incubated with TGF- $\beta+$ AZT (T + A). Pro-fibrotic gene expression was determined by RT-qPCR (a: Col1A1, b: FN). Data represents fold increase relative to the negative control (RM). One-way ANOVA followed by Tukey's post test was used for statistical analysis. Protein expression was determined by ELISA (c: pro-Col1A1) and one-way ANOVA followed by Bonferroni's post test was used for statistical analysis. For western blot analysis (d: FN; f: aSMA) one-way ANOVA followed by Tukey's post was used to analyze data. a Col1A1 gene expression was significantly reduced in control and IPF fibroblasts after AZT and TGF- $\beta$ treatment compared to TGF- $\beta$ alone $\left({ }^{* *} p\right.$-value $\leq 0.01,{ }^{* * *} p$-value $\left.\leq 0.001\right)$. b FN gene expression was not significantly altered after AZT neither in control nor in IPF fibroblasts compared to TGF- $\beta$ alone. c Collagen (pro-Col1A1) production was measured by ELISA in cell culture supernatant from control $(n=4)$ and IPF fibroblasts $(n=5)$. Additional AZT treatment induced a significant reduction in collagen secretion compared to TGF- $\beta$ treatment alone in IPF fibroblasts, but not in control fibroblasts ( ${ }^{*} p$-value $\leq 0.05$ ). Combined data is presented and data was normalized to $\beta 2 \mathrm{M}$, and means ( $+/-$ SEM) are presented as fold increase relative to the negative control RM. Combined data were analyzed. $\mathbf{d}$ FN protein expression was assessed by western blot analysis in whole cell lysates of control and IPF fibroblasts. FN protein expression was significantly reduced after AZT and TGF- $\beta$ treatment in IPF fibroblasts when directly compared to controls ( ${ }^{*} p$-value $\left.\leq 0.05\right)$. Combined quantified data of control and IPF patients $(n=4)$ relative to RM are shown. e Immunofluorescent staining of IPF fibroblasts visually revealed that aSMA fiber expression (red) was reduced after AZT treatment compared to TGF- $\beta$ alone and induced vacuolar formations. Magnification of 20x. Scale bar $=25 \mu$ M. $\mathbf{f}$ aSMA protein expression was significantly reduced only in IPF fibroblasts after AZT and TGF- $\beta$ treatment compared to TGF- $\beta$ alone $\left(^{* * *} p\right.$-value $\left.\leq 0.001\right)$. Combined quantified data of control and IPF patients $(n=4)$ relative to RM are shown. At least three independent experiments were performed

discrepancy was due to the high inter-individual variability of the TGF- $\beta$ treatment response we observed in primary lung fibroblasts. In control fibroblasts pro-Col1a1 protein expression was not reduced after addition of AZT, while IPF fibroblasts showed a significant reduction compared to controls (Fig. 1c). Similar, no reduction was seen for FN protein expression in control fibroblasts after AZT in addition to TGF- $\beta$, but FN protein expression was significantly reduced in IPF fibroblasts compared to controls (Fig. 1d). We speculate that differences between gene and protein expression might be influenced by enhanced post-transcriptional effects of AZT in IPF fibroblasts compared to controls. Last, we analyzed the myofibroblast differentiation marker $\alpha$ SMA by $\mathrm{qPCR}$, western blot and immunofluorescent staining. AZT treatment in addition to TGF- $\beta$ treatment significantly reduced $\alpha \mathrm{SMA}$ in control and IPF fibroblasts on gene expression level (Additional file 1: Figure S1C). Combination treatment with AZT showed a visual reduction of actin fibers in both control (not shown) and IPF fibroblasts (Fig. 1e). Notably, we observed fortuitously vacuolar formations after AZT treatment in most of control (not shown) and IPF fibroblasts in immunofluorescence staining for $\alpha$ SMA (Fig. 1e). Protein expression of $\alpha$ SMA was only significantly decreased in IPF fibroblasts after additional AZT treatment (Fig. 1f). IPF fibroblasts are considered to be more sensitive towards TGF- $\beta$ treatment [34]. With regards to $\alpha$ SMA protein expression, we could observe enhanced TGF- $\beta$ responsiveness in IPF fibroblasts compared to controls, although not statistically significant in our experiment (Fig. 1f).

\section{Azithromycin interferes with autophagy in control and IPF fibroblasts}

Vacuolar formations in Fig. 1e suggest that AZT might interfere with lysosomal and/or autophagic processes.
We thus performed an LC3B immunofluorescent staining as a marker for autophagosomes. As shown in Fig. 2a, AZT induced an accumulation of LC3B positive cells in control fibroblasts compared to AZT non-treated cells (RM and TGF- $\beta$ ). We further analyzed the protein expression of the autophagic markers LC3I, LC3II and p62. AZT treatment increased the LC3II/I ratio as a measurement of autophagic flux with and without TGF$\beta$ in both control and IPF fibroblasts (Fig. 2b). Increased ratio of LC3II/I indicates decreased autophagic flux and thus decreased autophagic activity [35]. For confirmation, we performed p62 western blot analysis which serves as a selective substrate for autophagy and is accumulated upon autophagy inhibition. While increase of p62 protein expression was not significant in control fibroblasts after combined AZT and TGF- $\beta$ treatment, IPF fibroblasts had a significant increase in $\mathrm{p} 62$ protein expression, and thus more autophagy reduction than controls (Fig. 2c).

\section{Azithromycin enhanced early apoptosis in IPF fibroblasts compared to controls}

To determine AZT cytotoxicity, we measured LDH release from cell supernatants after treatment. No cytotoxicity was observed in control fibroblasts treated with increasing concentration of AZT (Fig. 3a). Interestingly, we observed increased LDH levels in most but not all IPF fibroblasts after AZT with or without TGF- $\beta$ (Fig. $3 \mathrm{~b})$. No statistical difference could be detected due to inter-individual variability. Our results suggest that some IPF fibroblasts are more sensitive to AZT treatment than control fibroblasts. To further analyze AZT-induced cell death and apoptosis, we performed Annexin V/PI staining measured by flow cytometry. Both control and IPF fibroblasts showed increased early apoptosis defined as Annexin positive and PI negative signal after costimulation with AZT and TGF- $\beta$ compared to TGF- $\beta$ 


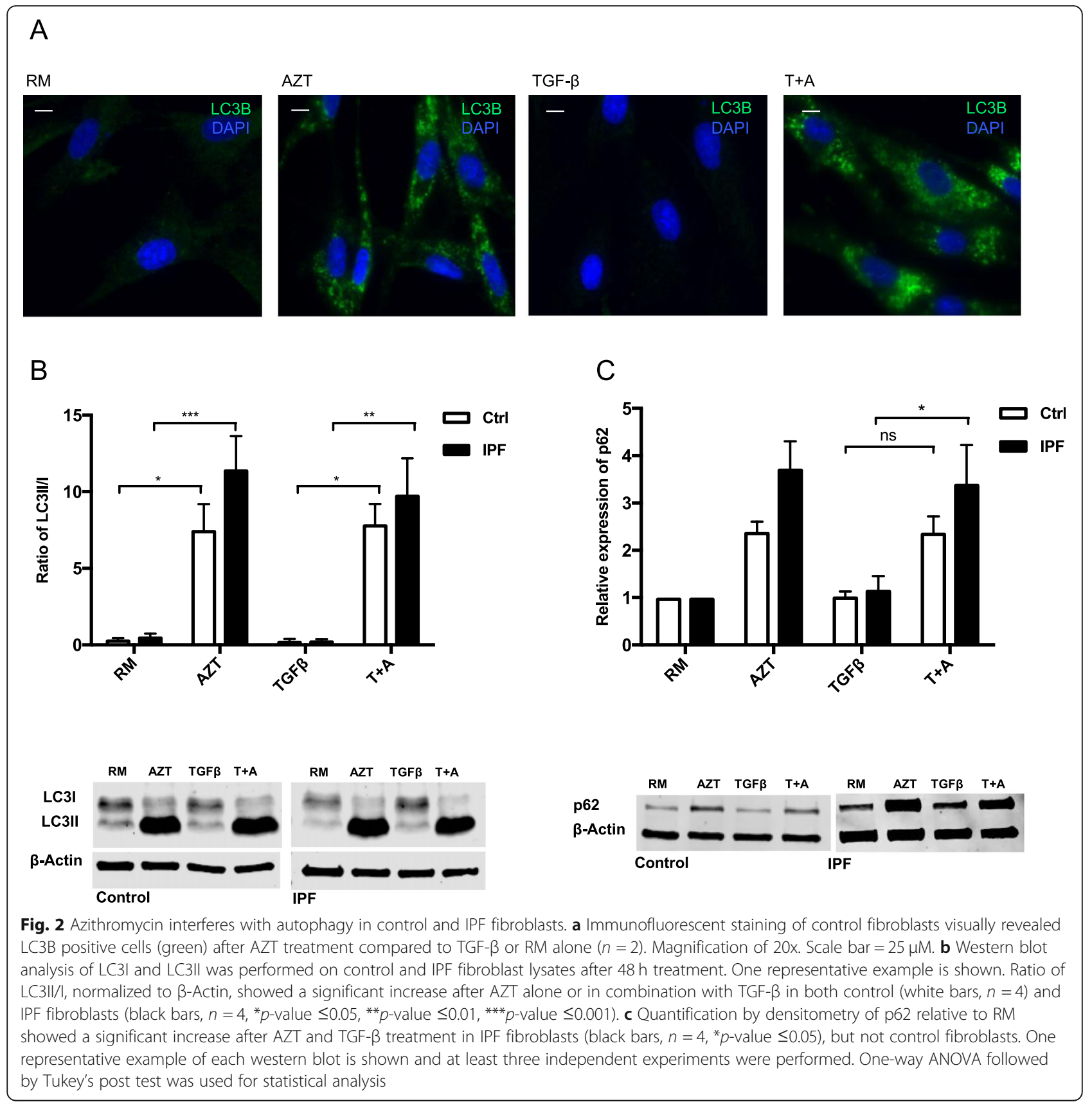

alone. When compared to controls, AZT and TGF- $\beta$ induced significantly higher early apoptotic levels in IPF fibroblasts (Fig. 3c). In addition, we performed Bcl-xL western blot analysis and observed a decrease in IPF fibroblasts compared to controls after TGF- $\beta$ and AZT (Fig. 3d), indicating reduced anti-apoptotic activity by Bcl-xL.

\section{Azithromycin alters several genes involved in lysosomal pathways}

To further elucidate the involved mechanisms of AZT effects, we performed microarray screening of control lung fibroblasts with and without AZT treatment. Microarray analysis showed the engagement of several lysosomal genes that were either up- or downregulated (Fig. 4a). A heat-map from microarray analysis with the 24 most differently regulated genes $(p<=0.005)$ (Fig. 4a) indicated that AZT treatment mostly impairs lysosomal genes. RAB7B, which is among others responsible for transportation of endosomes to the Golgi network [36] as well as degradation of proteins in lysosomes, [37] was downregulated after AZT treatment. Gene expression analysis revealed a greater decrease after TGF- $\beta$ and AZT in IPF compared to controls of RAB7B if compared 


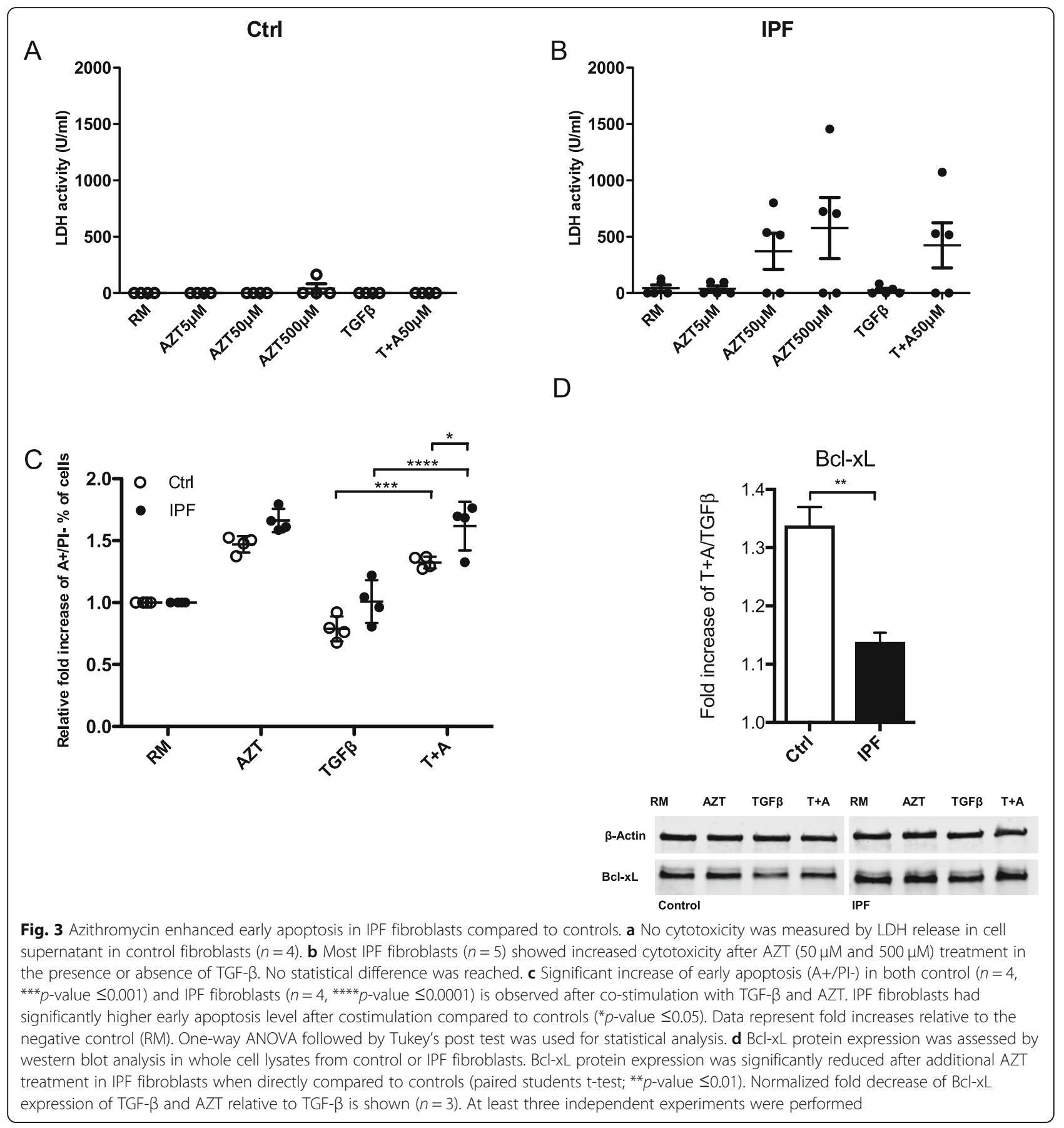

to TGF- $\beta$ stimulation alone (Fig. $4 \mathrm{~b}$ ). The lysosomal membrane marker TMEM55b, which was upregulated in our microarray analysis, was more increased on gene expression level after additional AZT treatment in IPF fibroblasts compared to controls (Fig. 4c). We further analyzed Cathepsin B (CTSB) and found a significant increase of CTSB after additional AZT treatment in control compared to IPF fibroblasts (Fig. 4d). Cathepsin C (CTSC), a lysosomal cysteine proteinase, [38] was downregulated after additional AZT treatment in control and
IPF fibroblasts (Fig. 4e). Last, we analyzed gene expression of Cathepsin D (CTSD) and did not see any significant changes after treatment (Fig. 4f).

\section{Azithromycin induces lysosomal accumulation in control and IPF fibroblasts}

AZT-induced vacuolar structures of control and IPF fibroblasts were analyzed in Hannover, Germany at the Institute for Anatomy by electron microscopy (EM). The vacuolar structures were identified in control (Fig. 5a1- 


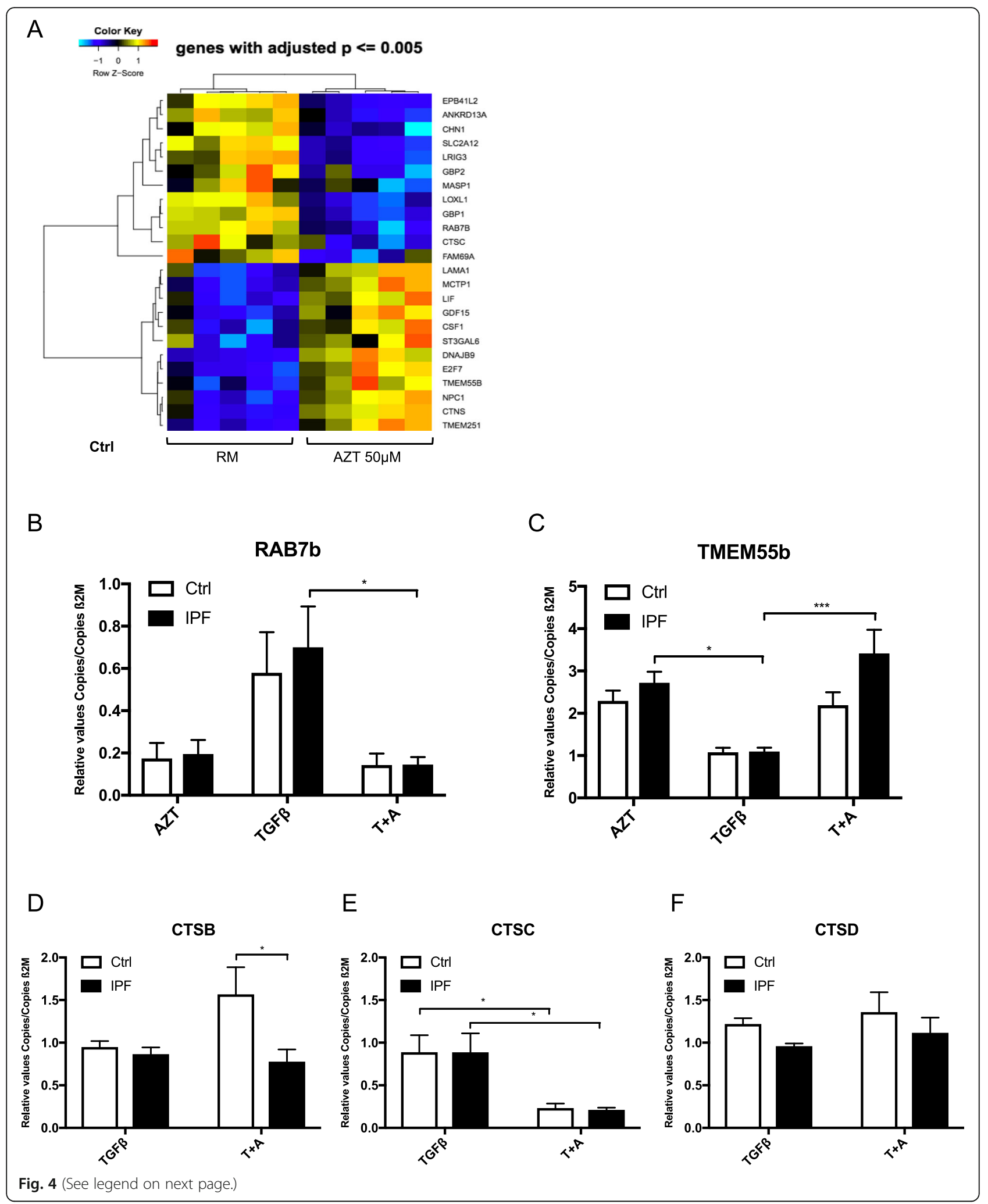




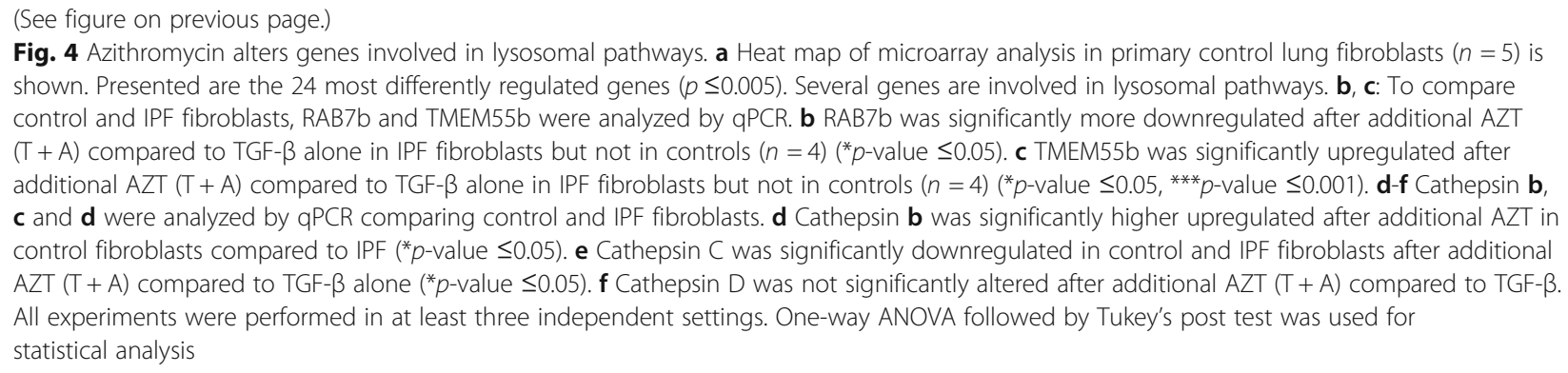

3) and IPF fibroblasts (Fig. 5a4-6) as late endosomes, lysosomes (Fig. 5a2 and 5) or autolysosomes (Fig.5a3 and a6). Lysosomal staining with LysoTracker (LT) green dye confirmed EM imaging finding. Lysosomes stained by LysoTracker green dye were clearly visible after AZT with or without TGF- $\beta$ treatment in both control and IPF fibroblasts (Fig. 5b). Lysosomal accumulation suggests that AZT might interfere with lysosomes and lysosomal function.

\section{Azithromycin affects vacuolar ATPases and impairs lysosomal $\mathrm{pH}$}

Microarray analysis (Fig. 4a) revealed the engagement of various vacuolar ATPases in control fibroblasts after AZT treatment as illustrated in Fig. 6a. Particularly ATP6V1B2 gene expression was increased, which is a proton pump important for lysosomal acidification and influences its function [39]. ATP6V1B2 gene expression was significantly upregulated after additional AZT compared to TGF- $\beta$ alone, but no significant difference was observed between control and IPF fibroblasts (Fig. 6b), neither on protein level (Additional file 1: Figure S3). We thus analyzed additional ATPases and found that gene expression of ATP6V0D2 was significantly less upregulated after additional AZT in IPF fibroblasts compared to controls (Fig. 6c). Last, we analyzed ATPase activity and function by measuring the lysosomal $\mathrm{pH}$. We observed a significant lysosomal $\mathrm{pH}$ increase after additional AZT treatment in control and IPF fibroblasts compared to TGF- $\beta$ alone. However, IPF fibroblasts had a significantly higher increase of $\mathrm{pH}$ and thus more impaired function after additional AZT when directly compared to control fibroblasts (Fig. 6d and e).

\section{Discussion}

Our study shows that AZT has anti-fibrotic and proapoptotic effects on primary fibroblasts and that these effects are enhanced in IPF fibroblasts compared to control fibroblasts. We confirmed that AZT reduces gene expression levels of pro-fibrotic genes after stimulation with TGF- $\beta$ in vitro in control as well as in IPF fibroblasts as recently reported [12]. In our study, AZT impairs lysosomal $\mathrm{pH}$ and autophagy in both, IPF and control fibroblasts but effects are enhanced in cells from IPF patients. Our study shows for the first time that AZT has enhanced anti-fibrotic effects on collagen, fibronectin, $\alpha$ SMA and pro-apoptotic markers in IPF fibroblasts compared to controls and that impaired lysosomal function might contribute to this finding. Our results further support the role of AZT as a potential treatment for IPF.

Studies with antimicrobial therapies have been previously proposed for IPF treatment as increased bacterial burden in the BAL of IPF predicted lung functional decline [40]. Preventive antibiotic treatment with Cotrimoxazole in IPF showed decreased mortality and lower oxygen needs [41]. However, effects of antibiotics, specifically macrolides, might go beyond the scope of its antibiotic effects and additional effects might even indirectly or directly alter disease course in IPF. Next to antimicrobial properties, AZT is known to reduce gastrointestinal reflux and aspiration [42]. Reflux is thought to contribute to IPF pathogenesis [43]. The acidic material of the reflux increases epithelial permeability and as a consequence promotes fibrogenesis [43]. Moreover, direct anti-fibrotic effects of AZT have been previously described in the bleomycin mouse model of lung fibrosis. Wuyts et al. showed that collagen deposition and spindle cell proliferation were reduced after AZT treatment [14]. AZT has been described to highly accumulate in tissues and fibroblasts [44] achieving up to 100-fold higher concentrations than those in plasma [15]. This accumulation might even amplify the antifibrotic effects of AZT on fibroblasts in the fibrotic lung. Anti-fibrotic effects have also been found with other macrolides. A derivative of Erythromycin, EM703, was able to reduce the transcription of collagen in normal and scleroderma fibroblasts [45]. EM703 also downregulated collagen in the bleomycin mouse model by modulating TGF- $\beta$ signaling in lung fibroblasts, suggesting a potential role for macrolides in fibrosis treatment [46]. While anti-fibrotic effects have been described for macrolides, the effects in diseased and healthy cells remain unexplored. Different behavior of primary diseased cells and healthy controls is commonly observed [24]. It has been found that IPF fibroblasts are more resistant to 
A

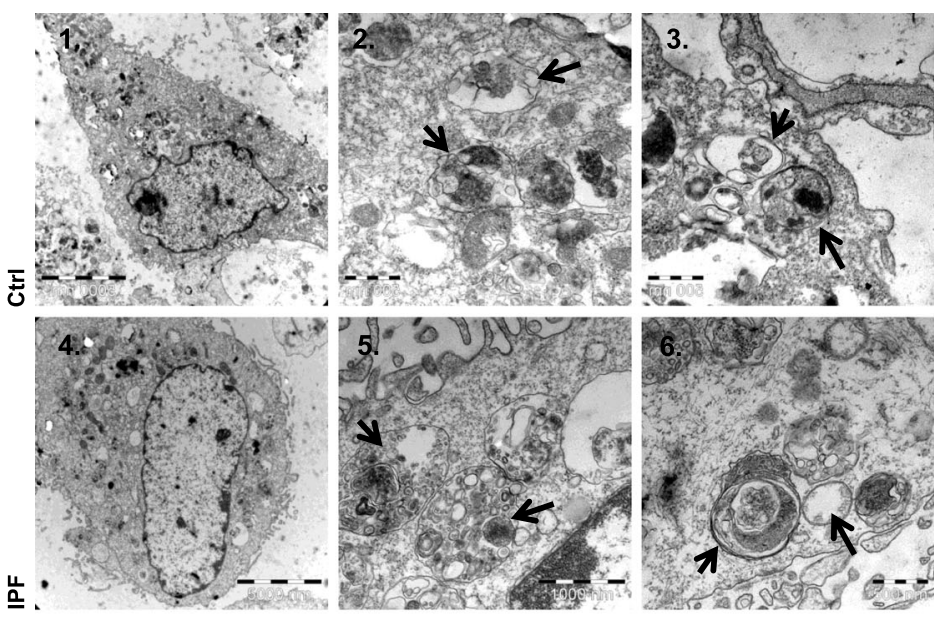

B

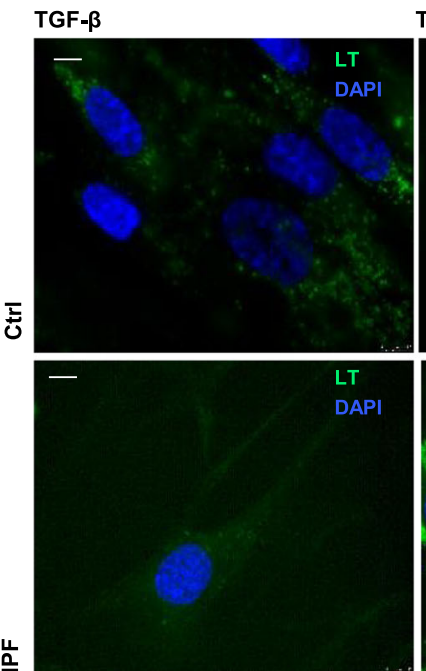

$\mathbf{T}+\mathbf{A}$

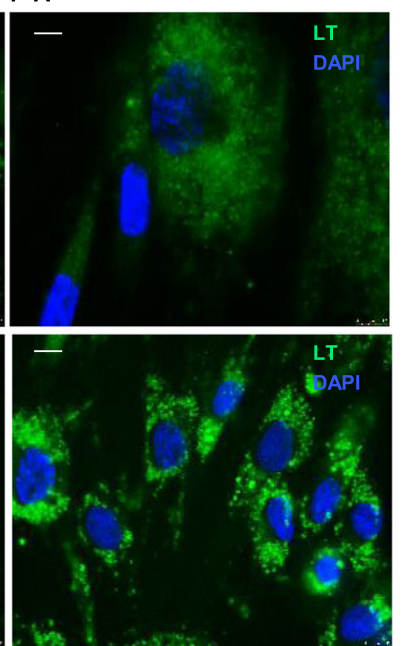

Fig. 5 Azithromycin induces lysosomal accumulation in control and IPF fibroblasts. a Control (A1-3) and IPF fibroblasts (A4-6) were treated with AZT for $24 \mathrm{~h}$, fixed and analyzed by electron microscopy. $(A 1,4)$ Overview, $(A 2,5)$ late endosomes or lysosomes (arrows), (A3, 6) autolysosomes, double membrane (arrows). b Lysotracker green staining in control (upper images, $n=3$ ) and IPF fibroblasts (lower images, $n=3$ ) after $24 \mathrm{~h}$ treatment with AZT in presence or absence of TGF- $\beta$ confirmed the vacuolar structures as lysosomes. Magnification of $63 x$. Scale bar = $10 \mu M$. All experiments were performed in three independent experiments

collagen matrix induced cell death compared to controls [47]. Vuga et al. found that upregulation of the WNT5A gene was responsible for apoptosis resistance in fibroblasts from fibrotic lungs compared to controls [48]. Moreover, it has been shown that IPF fibroblasts have decreased FoxO3a expression causing low autophagy levels [49]. In IPF, decreased autophagy marker levels are already observed at baseline [9]. Interestingly, autophagy induction is considered anti-fibrotic and the autophagy inducer rapamycin protects against bleomycin induced lung fibrosis [11]. Our present findings are intriguing and indicate that also inhibition of autophagy by AZT has anti-fibrotic effects [12]. TGF- $\beta$ the main pro- fibrotic marker driving lung fibrosis has been shown to induce autophagy in lung fibroblasts [50]. These controversial findings raise the question of which approach would be most beneficial in IPF patients: An increase or a reduction of autophagy? Today, the role of autophagy on fibrosis remains unclear and our study is unable to fully answer this question. To maintain proper cell function a balanced autophagic flux is crucial. Autophagy is a cellular process that is induced in both physiological as well as pathophysiological conditions and it is essential for cell survival to maintain a fine balance between protein synthesis and degradation [51]. 


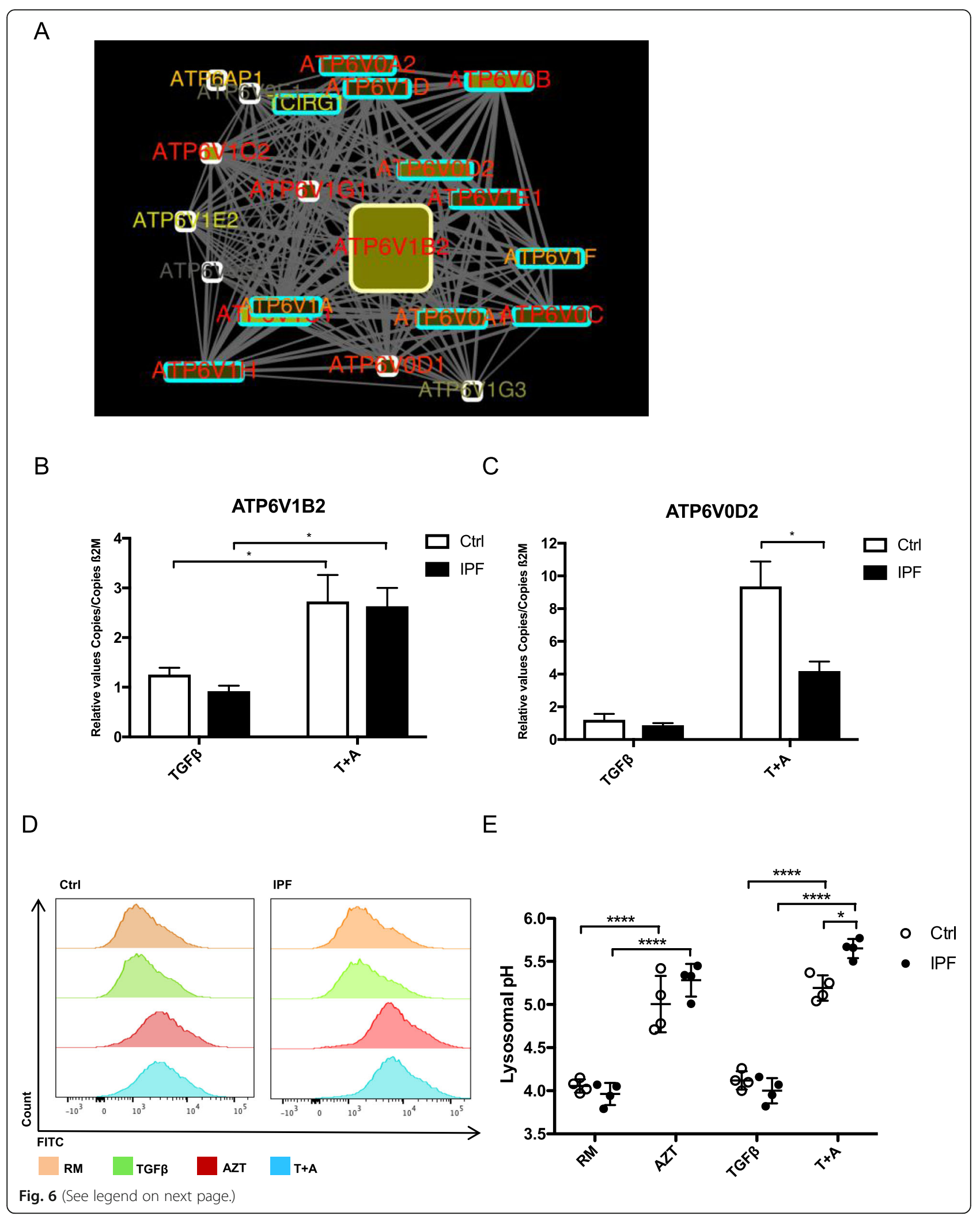


(See figure on previous page.)

Fig. 6 Azithromycin affects vacuolar ATPases and impairs the lysosomal pH. a Microarray analysis revealed the engagement of various vacuolar ATPases. Particularly ATP6V1B2 gene expression was increased, which suggests the involvement of lysosomal acidification. b ATP6V1B2 gene expression was significantly upregulated in control and IPF fibroblasts after additional AZT (T + A) compared to TGF- $\beta$ alone

$\left({ }^{*} p\right.$-value $\left.\leq 0.0, n=4\right)$, although no difference was observed for ATP6V1B2 between controls and IPF-FB. c ATP6V0D2 gene expression was significantly higher upregulated in controls after additional AZT $(T+A)$ compared to IPF ( ${ }^{*} p$-value $\left.\leq 0.05, n=4\right)$. $\mathbf{d}$ A representative histogram of control and IPF treated fibroblasts measured by flow cytometry is shown. Notably, a shift of the lysosomal pH represented by the FITC signal is seen after AZT treatment in both control and IPF fibroblasts and slightly stronger in the IPF fibroblasts. Combined data $(n=4$, each) from independent experiments are shown in e AZT in the presence or absence of TGF- $\beta$ induced a significant increase of the lysosomal pH in both control $\left(n=4,{ }^{* * * *} p\right.$-value $\left.\leq 0.0001\right)$ and IPF fibroblasts $\left(n=4,{ }^{* * *} p\right.$-value $\left.\leq 0.0001\right)$. Lysosomal pH was significantly different between control and IPF fibroblasts after additional AZT ( ${ }^{*} p$-value $\leq 0.05$ ). All experiments were performed in three independent settings. One-way ANOVA followed by Tukey's post test was used for statistical analysis

Autophagy inhibition is observed after AZT treatment and prevented myofibroblast differentiation through profibrotic NOX4 suppression [12], however healthy fibroblasts have not been compared to IPF fibroblasts so far and the entire mechanism of anti-fibrotic effects of AZT is not fully understood. Our observation of intracellular vacuolar formation and impaired lysosomal function after AZT is in line with several published studies where AZT induced cytoplasmic vacuoles suggested the involvement of lysosomal function [52, 53]. Lysosomal accumulation might occur after autophagosome clearance is blocked and autophagosomal degradation is impaired.

Lysosomes are organelles with a low internal $\mathrm{pH}$ of 4.55 which is known to be regulated by vacuolar ATPases [54]. The main function is the degradation of cytoplasmic material, including damaged organelles, proteins and lipids [54]. Low lysosomal $\mathrm{pH}$ is crucial for degradation of cytoplasmic material by lysosomal hydrolases [55]. We show that AZT affects vacuolar ATPases and its function is impaired. Furthermore, AZT affects several lysosomal genes such as Rab7b. Interestingly, Rab7b was found to be crucial for actin filament organization and remodeling. Rab7b reduction prevented stress fiber formation, reduced cell migration and adhesion to fibronectin [56]. We speculate that downregulation of the lysosomal gene Rab7b could be one possible anti-fibrotic mechanism of AZT. In addition, enhanced collagen degradation through lysosomal recycling impairment was shown in renal fibrosis by inhibition of Cathepsin D [57]. Lysosomal impairment with chloroquine, an endo/lysosome inhibitor had similar effects on collagen degradation [57]. Bafilomycin is another lysosomal vacuolar ATPase inhibitor which inhibits the autophagic flux by preventing lysosomal acidification and/or blocking the fusion of lysosomes with autophagosomes $[58,59]$. Interestingly, it has been found that Bafilomycin reduced collagen and fibronectin in human atrial myofibroblasts, but did not affect Smad2/3 phosphorylation [60]. In line with this finding, we and others also have found that AZT did not influence SMAD phosphorylation (Additional file 1: Figure S2) [12]. Although Bafilomycin is a widely used autophagy inhibitor acting on the lysosomal vacuolar ATPase in vitro, it is not approved for therapeutical use in humans due to acute cytotoxic effects in vivo [61]. AZT has been used for over 30 years as an antibiotic without significant adverse health effects [15]. Although AZT represents a promising future therapeutic option for fibrosis, antibiotic resistance should be considered as long-term use of AZT was recently shown to induce macrolide resistance in severe asthma patients [62].

In addition to enhanced anti-fibrotic effects of AZT in IPF-FB, we have observed increased apoptosis of fibroblasts after AZT treatment compared to control-FB. We showed that AZT induces a stronger increase of the lysosomal $\mathrm{pH}$ in IPF-FB, which has been proposed to lead to lysosomal membrane permeabilization and trigger the socalled lysosomal apoptotic pathway [63, 64]. Furthermore, it has been demonstrated that lysomotropic compounds are able to increase lysosomal $\mathrm{pH}$ and as a consequence decrease enzyme activity and proposed to impair lysosomal function [65]. Similar, a recent study has found that lysosomal $\mathrm{pH}$ increase with Verteporfin induced cell toxicity in malignant hepatocellular cells only [66].

Today, two drugs approved for IPF treatment (Nintedanib and Pirfenidone) are able to slow down disease progression, but adverse effects are common and no improvement can be achieved in most patients. New therapeutic treatments and treatment combinations are thus urgently needed to not only stop, but also to reverse fibrosis. AZT is a well tolerated macrolide antibiotic with tolerable side effects and could be a potential new additional therapeutic drug for IPF, but additional in vivo studies and prospective clinical trials are needed to confirm its anti-fibrotic effects.

\section{Conclusions}

Our study shows that AZT has a greater anti-fibrotic effect regarding collagen and fibronectin secretion as well as myofibroblast differentiation in IPF compared to controls. Moreover, AZT has enhanced pro-apoptotic effects on IPF fibroblasts. The impaired lysosomal function in IPF fibroblasts after additional AZT treatment could explain cell damage with higher apoptosis levels in IPF fibroblasts. Our findings may stimulate new treatment strategies for IPF patients, but need to be tested in controlled clinical trials. 


\section{Supplementary information}

Supplementary information accompanies this paper at https://doi.org/10. 1186/s12931-020-1275-8.

Additional file 1. Figure S1. Azithromycin reduces gene expression of fibronectin and ASMA in IPF and control fibroblasts. Figure S2. SMAD phosporylation is not influenced by Azithromycin in IPF and control fibroblasts. Figure S3. Azithromycin does not alter protein expression of ATP6V1B2 in IPF and control fibroblasts.

\section{Acknowledgements}

We would like to acknowledge the expert input and advice provided by Dr. Sean Hall, PD Dr. Fabian Blank and PD Dr. Thomas Marti from the Department for BioMedical Research of the University of Bern, Switzerland. Microarray analysis was performed using Affymetrix analysis in the laboratory for fluorescent Bioanalysis by the Kompetenzzentrum Fluoreszente Bioanalytik (KFB), Regensburg, Germany. Microscopic pictures were acquired at the Microscopy Imaging Center at the University of Bern, Switzerland. FACS analysis was performed at the FACSlab facilty of the University of Bern, Switzerland. Prof B. Crestani from Paris kindly provided our study with isolated fibroblasts from IPF as well as control patients.

\section{Author's contributions}

$M F$, and KK conception and design of research; KK, SB, JG, SE, AS and RS performed and analyzed experiments; CS performed and analyzed microarrays, LK performed and analyzed EM imaging; MF and KK interpreted results of experiments. KK prepared figures, MF and KK drafted the manuscript. MF, KK, JG, LK, NH, SE and TG edited and revised manuscript. All authors approved final version of the manuscript for submission.

\section{Funding}

Our study was funded by a research grant from the Lungenliga, Bern.

\section{Availability of data and materials}

All data generated or analyzed in this study is available from the corresponding author upon request. RNA microarray data from control lung fibroblasts treated with Azithromycin versus non-treated can be downloaded from the ArrayExpress database at EMBL-EBI (www.ebi.ac.uk/arrayexpress) under accession number E-MTAB-8488.

\section{Ethics approval and consent to participate}

The ethics committee of Bern, Switzerland approved this study (KEK-BE:042/ 2015). All study participants provided their informed written consent.

\section{Consent for publication}

Not applicable.

\section{Competing interests}

The authors declare that they have no competing interests.

\section{Author details}

${ }^{1}$ Department of Pulmonary Medicine, Inselspital, Bern University Hospital, University of Bern, $\mathrm{CH}-3010$ Bern, Switzerland. ${ }^{2}$ Department for BioMedical Research, University of Bern, Bern, Switzerland. ${ }^{3}$ Graduate School for Cellular and Biomedical Sciences, University of Bern, Bern, Switzerland. ${ }^{4}$ Department of Visceral Surgery and Medicine, Department for BioMedical Research, Inselspital, Bern University Hospital and University of Bern, 3010 Bern, Switzerland. ${ }^{5}$ Alveolix AG, Murtenstrasse 50, 3008 Bern, Switzerland. ${ }^{6}$ ARTORG Center for Biomedical Engineering Research, Organs-on-Chip Technologies, University of Bern, Bern, Switzerland. ${ }^{7}$ Bioinformatics Unit and SIB Swiss Institute of Bioinformatics, University of Bern, Bern, Switzerland. ${ }^{8}$ Institute of Functional and Applied Anatomy, Hannover Medical School, Hannover, Germany. ${ }^{9}$ Biomedical Research in Endstage and Obstructive Lung Disease Hannover (BREATH), Member of the German Center for Lung Research (DZL), Hannover, Germany.
Received: 2 November 2019 Accepted: 1 January 2020

Published online: 15 January 2020

\section{References}

1. Ley B, Collard HR, King TE. Clinical Course and Prediction of Survival in Idiopathic Pulmonary Fibrosis. Am J Respir Crit Care Med [Internet]. 2011;183:431-40 Available from: http://www.ncbi.nlm.nih.gov/pubmed/20935110 [cited 2019 Oct 1].

2. Raghu G, Collard HR, Egan JJ, Martinez FJ, Behr J, Brown KK, et al. An official ATS/ ERS/JRS/ALAT statement: idiopathic pulmonary fibrosis: evidence-based guidelines for diagnosis and management. Am J Respir Crit Care Med. 2011;183:788-824.

3. Crestani B, Huggins JT, Kaye M, Costabel U, Glaspole I, Ogura T, et al. Longterm safety and tolerability of nintedanib in patients with idiopathic pulmonary fibrosis: results from the open-label extension study, INPULSISON. Lancet Respir Med. 2019;7:60-8.

4. Margaritopoulos GA, Trachalaki A, Wells AU, Vasarmidi E, Bibaki E, Papastratigakis $\mathrm{G}$, et al. Pirfenidone improves survival in IPF: results from a real-life study. BMC Pulm Med [Internet]. 2018;18:177 Available from: https://bmcpulmmed. biomedcentral.com/articles/10.1186/s12890-018-0736-z [cited 2019 Sep 9].

5. Geiser T. Idiopathic pulmonary fibrosis-a disorder of alveolar wound repair? Swiss Med Wkly [Internet]. 2003;133:405-11 Available from: http://www.ncbi. nlm.nih.gov/pubmed/14562190 [cited 2019 Oct 1].

6. Phan SH. Genesis of the myofibroblast in lung injury and fibrosis. Proc Am Thorac Soc [Internet]. 2012;9:148-52 Available from: http://www.ncbi.nlm. nih.gov/pubmed/22802289 [cited 2019 Aug 28].

7. Upagupta C, Shimbori C, Alsilmi R, Kolb M. Matrix abnormalities in pulmonary fibrosis. Eur Respir Rev [Internet]. 2018;27:180033 Available from: http://www.ncbi.n/m.nih.gov/pubmed/29950306 [cited 2019 Sep 30].

8. Biernacka A, Dobaczewski M, Frangogiannis NG. TGF- $\beta$ signaling in fibrosis. Growth Factors. 2011;29:196-202

9. Araya J, Kojima J, Takasaka N, Ito S, Fujii S, Hara H, et al. Insufficient autophagy in idiopathic pulmonary fibrosis. Am J Physiol Cell Mol Physiol [Internet]. 2013;304:L56-69 Available from: http://www.ncbi.nlm.nih.gov/ pubmed/23087019 [cited 2019 Oct 1].

10. Sosulski ML, Gongora R, Danchuk S, Dong C, Luo F, Sanchez CG. Deregulation of selective autophagy during aging and pulmonary fibrosis: the role of TGFß1. Aging Cell. 2015;14:774-83. Available from: http://www. ncbi.nlm.nih.gov/pubmed/26059457.

11. Patel AS, Lin L, Geyer A, Haspel JA, An CH, Cao J, et al. Autophagy in idiopathic pulmonary fibrosis. PLoS One. 2012;7:e41394. Available from: http://www.ncbi.nlm.nih.gov/pubmed/22815997.

12. Tsubouchi K, Araya J, Minagawa S, Hara H, Ichikawa A, Saito N, et al. Azithromycin attenuates myofibroblast differentiation and lung fibrosis development through proteasomal degradation of NOX4. Autophagy. 2017; 13:1420-34. Available from: https://doi.org/10.1080/15548627.2017.1328348.

13. Amara N, Goven D, Prost F, Muloway R, Crestani B, Boczkowski J. NOX4/ $\mathrm{NADPH}$ oxidase expression is increased in pulmonary fibroblasts from patients with idiopathic pulmonary fibrosis and mediates TGFbeta1-induced fibroblast differentiation into myofibroblasts. Thorax. 2010;65:733-8. Available from: http://www.ncbi.nlm.nih.gov/pubmed/20685750.

14. Wuyts WA, Willems S, Vos R, Vanaudenaerde BM, De Vleeschauwer SI, Rinaldi $M$, et al. Azithromycin reduces pulmonary fibrosis in a bleomycin mouse model. Exp Lung Res. 2010;36:602-14.

15. Parnham MJ, Haber VE, Giamarellos-Bourboulis EJ, Perletti G, Verleden GM, Vos R. Azithromycin: Mechanisms of action and their relevance for clinical applications. Pharmacol Ther [Internet]. 2014;143:225-45 Available from: http://www.ncbi.nlm.nih.gov/pubmed/24631273 [cited 2019 Oct 11].

16. McDonald PJ, Pruul H. Phagocyte uptake and transport of azithromycin. Eur J Clin Microbiol Infect Dis [Internet]. 1991;10:828-33 Available from: http:// www.ncbi.nlm.nih.gov/pubmed/1662626 [cited 2019 Oct 1]

17. Martinez FJ, Curtis JL, Albert R. Role of macrolide therapy in chronic obstructive pulmonary disease. Int. J. COPD. 2008:331-50.

18. Piacentini GL, Peroni DG, Bodini A, Pigozzi R, Costella S, Loiacono A, et al. Azithromycin reduces bronchial hyperresponsiveness and neutrophilic airway inflammation in asthmatic children: a preliminary report. Allergy Asthma Proc. 2007:28:194-8.

19. Wolter JM, Seeney SL, McCormack JG. Macrolides in cystic fibrosis: is there a role? Am J Respir Med. 2002:1:235-41.

20. Idris SF, Chilvers ER, Haworth C, McKeon D, Condliffe AM. Azithromycin therapy for neutrophilic airways disease: myth or magic? Thorax. 2009:64: 186-9. Available from: http://www.ncbi.nlm.nih.gov/pubmed/19252016. 
21. Song JW, Hong S-B, Lim C-M, Koh Y, Kim DS. Acute exacerbation of idiopathic pulmonary fibrosis: incidence, risk factors and outcome. Eur Respir J Off J Eur Soc Clin Respir Physiol. 2011;37:356-63.

22. Kawamura K, Ichikado K, Yasuda Y, Anan K, Suga M. Azithromycin for idiopathic acute exacerbation of idiopathic pulmonary fibrosis: a retrospective single-center study. BMC Pulm Med. 2017:17:1-8.

23. Macaluso C, Maritano Furcada J, Alzaher O, Chaube R, Chua F, Wells AU, et al. The potential impact of azithromycin in idiopathic pulmonary fibrosis. Eur. Respir. J. NLM (Medline); 2019.

24. Schögler A, Stokes AB, Casaulta C, Regamey N, Edwards MR, Johnston SL, et al. Interferon response of the cystic fibrosis bronchial epithelium to major and minor group rhinovirus infection. J Cyst Fibros. 2016;15:332-9. Available from: https://dx.doi.org/10.1016/j.jcf.2015.10.013.

25. Joannes A, Brayer S, Besnard V, Marchal-Sommé J, Jaillet M, Mordant $P$, et al. FGF9 and FGF18 in idiopathic pulmonary fibrosis promote survival and migration and inhibit myofibroblast differentiation of human lung fibroblasts in vitro. Am J Physiol Cell Mol Physiol. 2016; 310:L615-29.

26. Ebener S, Barnowski S, Wotzkow C, Marti TM, Lopez-Rodriguez E, Crestani B, et al. Toll-like receptor 4 activation attenuates profibrotic response in control lung fibroblasts but not in fibroblasts from patients with IPF. Am J Physiol Cell Mol Physiol. 2016;312:L42-55.

27. Alves MP, Schögler A, Ebener S, Vielle NJ, Casaulta C, Jung A, et al. Comparison of innate immune responses towards rhinovirus infection of primary nasal and bronchial epithelial cells. Respirology. 2016;21:304-12.

28. Eriksson I, Öllinger K, Appelqvist H. Analysis of Lysosomal pH by Flow Cytometry Using FITC-Dextran Loaded Cells. Methods Mol Biol [Internet]. 2017;1594:179-89 Available from: http://www.ncbi.nlm.nih.gov/pubmed/2 8456983 [cited 2019 Aug 29].

29. Mühlfeld C, Knudsen L, Ochs M. Stereology and morphometry of lung tissue. Methods Mol Biol. 2012;931:367-90. https://doi.org/0.1007/978-1-62 703-056-4_18.

30. Dai M, Wang P, Boyd AD, Kostov G, Athey B, Jones EG, et al. Evolving gene/ transcript definitions significantly alter the interpretation of GeneChip data. Nucleic Acids Res [Internet]. 2005;33:e175 Available from: http://www.ncbi. nlm.nih.gov/pubmed/16284200 [cited 2019 Oct 26].

31. Irizarry RA, Hobbs B, Collin F, Beazer-Barclay YD, Antonellis KJ, Scherf U, et al. Exploration, normalization, and summaries of high density oligonucleotide array probe level data. Sel Work Terry Speed. Springer New York; 2012. p. 601-616.

32. Ritchie ME, Phipson B, Wu D, Hu Y, Law CW, Shi W, et al. Limma powers differential expression analyses for RNA-sequencing and microarray studies. Nucleic Acids Res. 2015;43:e47. https://doi.org/10.1093/nar/gkv007.

33. Simillion C, Liechti R, Lischer HEL, loannidis V, Bruggmann R. Avoiding the pitfalls of gene set enrichment analysis with SetRank. BMC Bioinformatics. 2017;18. https://doi.org/10.1186/s12859-017-1571-6.

34. Murray LA, Argentieri RL, Farrell FX, Bracht $M$, Sheng $H$, Whitaker $B$, et al. Hyper-responsiveness of IPF/UIP fibroblasts: interplay between TGF 31 , IL-13 and CCL2. Int J Biochem Cell Biol. 2008;40:2174-82.

35. Mizushima N, Yoshimori T. How to Interpret LC3 Immunoblotting. Autophagy [Internet]. 2007;3:542-5 Available from: http://www.tandfonline. com/doi/abs/10.4161/auto.4600 [cited 2019 Oct 11].

36. Progida C, Cogli L, Piro F, De Luca A, Bakke O, Bucci C. Rab7b controls trafficking from endosomes to the TGN. J Cell Sci. 2010;123:1480-91.

37. Bucci C, Bakke O, Progida C. Rab7b and receptors trafficking. Commun Integr Biol. 2010:401-4.

38. Ruffell B, Affara NI, Cottone L, Junankar S, Johansson M, DeNardo DG, et al. Cathepsin $C$ is a tissue-specific regulator of squamous carcinogenesis. Genes Dev. 2013;27:2086-98.

39. Yuan Y, Zhang J, Chang Q, Zeng J, Xin F, Wang J, et al. De novo mutation in ATP6V1B2 impairs lysosome acidification and causes dominant deafness-onychodystrophy syndrome. Cell Res [Internet]. 2014; 24:1370-3 Available from: http://www.nature.com/articles/cr201477 [cited 2019 Aug 21].

40. Molyneaux PL, Cox MJ, Willis-Owen SAG, Mallia P, Russell KE, Russell $A M$, et al. The role of bacteria in the pathogenesis and progression of idiopathic pulmonary fibrosis. Am J Respir Crit Care Med. 2014;190: 906-13.

41. Shulgina L, Cahn AP, Chilvers ER, Parfrey H, Clark AB, Wilson ECF, et al. Treating idiopathic pulmonary fibrosis with the addition of co-trimoxazole: a randomised controlled trial. Thorax. 2013;68:155-62.
42. Mertens V, Blondeau K, Pauwels A, Farre R, Vanaudenaerde B, Vos R, et al. Azithromycin reduces Gastroesophageal reflux and aspiration in lung transplant recipients. Dig Dis Sci. 2009;54:972-9.

43. Kreuter M, Raghu G. Gastro-oesophageal reflux and idiopathic pulmonary fibrosis: the heart burn in patients with IPF can no longer be silent. Eur Respir J [Internet]. 2018;11-13. Available from: http://dx.doi.org/https://doi. org/10.1183/13993003.00921-2018

44. Gladue RP, Snider ME. Intracellular accumulation of azithromycin by cultured human fibroblasts. Antimicrob Agents Chemother. 1990;34:105660. Available from: http://www.ncbi.nlm.nih.gov/pubmed/2168141.

45. Ikeda H, Sunazuka T, Suzuki H, Hamasaki Y, Yamazaki S, Omura S, et al. EM703, the new derivative of erythromycin, inhibits transcription of type I collagen in normal and scleroderma fibroblasts. J Dermatol Sci. 2008;49: 195-205.

46. Li YJ, Azuma A, Usuki J, Abe S, Matsuda K, Sunazuka T, et al. EM703 improves bleomycin-induced pulmonary fibrosis in mice by the inhibition of TGF- $\beta$ signaling in lung fibroblasts. Respir Res. 2006;7:1-13.

47. Nho RS, Hergert P. IPF Fibroblasts Are Desensitized to Type I Collagen Matrix-Induced Cell Death by Suppressing Low Autophagy via Aberrant Akt/mTOR Kinases. In: Gullberg D, editor. PLoS One [Internet], vol. 9; 2014. p. e94616. Available from: http://www.ncbi.nlm.nih.gov/pubmed/24728102 [cited 2019 Oct 11].

48. Vuga $L$, Ben-Yehudah A, Kovkarova-Naumovski E, Oriss T, Gibson KF, Feghali-Bostwick C, et al. WNT5A is a regulator of fibroblast proliferation and resistance to apoptosis. Am J Respir Cell Mol Biol. 2009;41:583-9.

49. Im J, Hergert P, Nho RS. Reduced FoxO3a expression causes low autophagy in idiopathic pulmonary fibrosis fibroblasts on collagen matrices. Am J Physiol Cell Mol Physiol. 2015;309:L552-61. Available from: https://www. physiology.org/doi/10.1152/ajplung.00079.2015.

50. Ghavami S, Yeganeh B, Zeki AA, Shojaei S, Kenyon NJ, Ott S, et al. Autophagy and the unfolded protein response promote profibrotic effects of TGF- $\beta 1$ in human lung fibroblasts. Am J Physiol Cell Mol Physiol. 2017; 314:L493-504

51. Ren J, Taegtmeyer $\mathrm{H}$. Too much or not enough of a good thing - The Janus faces of autophagy in cardiac fuel and protein homeostasis. J Mol Cell Cardiol [Internet]. 2015;84:223-6 Available from: http://www.ncbi.nlm. nih.gov/pubmed/25771142 [cited 2019 Oct 11].

52. Stamatiou R, Paraskeva E, Boukas K, Gourgoulianis Kl, Molyvdas PA, Hatziefthimiou AA. Azithromycin has an antiproliferative and autophagic effect on airway smooth muscle cells. Eur Respir J. 2009;34:721-30.

53. Renna M, Schaffner C, Brown K, Shang S, Tamayo MH, Hegyi K, et al. Azithromycin blocks autophagy and may predispose cystic fibrosis patients to mycobacterial infection. J Clin Invest. 2011;121:3554-63. Available from: https://www.jci.org/articles/29389.

54. Mrschtik M, Ryan KM. Lysosomal proteins in cell death and autophagy. FEBS J. 2015:1858-70.

55. Maxson ME, Grinstein S. The vacuolar-type H+-ATPase at a glance - more than a proton pump. J Cell Sci. 2014;127:4987-93. Available from: http:// www.ncbi.nlm.nih.gov/pubmed/25453113.

56. Borg M, Bakke O, Progida C. A novel interaction between Rab7b and actomyosin reveals a dual role in intracellular transport and cell migration. J Cell Sci. 2014;127:4927-39. https://doi.org/10.1242/jcs.155861.

57. Fox C, Cocchiaro P, Oakley F, Howarth R, Callaghan K, Leslie J, et al. Inhibition of lysosomal protease cathepsin $\mathrm{D}$ reduces renal fibrosis in murine chronic kidney disease. Sci Rep [Internet]. 2016;6 Available from: www.nature.com/scientificreports [cited 2019 Aug 21].

58. Mauvezin C, Nagy P, Juhász G, Neufeld TP. Autophagosome-lysosome fusion is independent of V-ATPase-mediated acidification. Nat Commun. 2015;6:7007. Available from: http://www.ncbi.nlm.nih.gov/pubmed/259596 78.

59. Mauvezin C, Neufeld TP. Bafilomycin A1 disrupts autophagic flux by inhibiting both V-ATPase-dependent acidification and Ca-P60A/SERCAdependentautophagosome-lysosome fusion. Autophagy. 2015;11:1437-8. Available from: http://www.ncbi.n/m.nih.gov/pubmed/26156798.

60. Ghavami S, Cunnington RH, Gupta S, Yeganeh B, Filomeno KL, Freed DH, et al. Autophagy is a regulator of TGF- $\beta 1$-induced fibrogenesis in primary human atrial myofibroblasts. Cell Death Dis [Internet]. Nature Publishing Group; 2015 ;6:e1696. Available from: http://www.nature.com/articles/cddis2 01536 [cited 2019 Aug 9]

61. Keeling DJ, Herslöf M, Ryberg B, Sjögren S, Sölvell L. Vacuolar H(+)-ATPases. Targets for Drug Discovery? Ann N Y Acad Sci [Internet]. 1997 ;834:600-608. 
Available from: [cited 2019 Aug 29] http://doi.wiley.com/https://doi.org/10 1111/j.1749-6632.1997.tb52329.x

62. Taylor SL, Leong LEX, Mobegi FM, Choo JM, Wesselingh S, Yang IA, et al. Long-Term Azithromycin Reduces Haemophilus influenzae and Increases Antibiotic Resistance in Severe Asthma. Am J Respir Crit Care Med [Internet]. 2019 ;200:309-317. Available from: [cited 2019 Aug 28] https://www. atsjournals.org/doi/https://doi.org/10.1164/rccm.201809-17390C

63. Cirman T, Orešić K, Mazovec GD, Turk V, Reed JC, Myers RM, et al. Selective disruption of lysosomes in HeLa cells triggers apoptosis mediated by cleavage of bid by multiple papain-like Lysosomal Cathepsins. J Biol Chem. 2004;279:3578-87.

64. Droga-Mazovec G, Bojič L, Petelin A, Ivanova S, Romih R, Repnik U, et al. Cysteine cathepsins trigger caspase-dependent cell death through cleavage of bid and antiapoptotic BCl-2 homologues. J Biol Chem. 2008;283:19140-50.

65. Lu S, Sung T, Lin N, Abraham RT, Jessen BA. Lysosomal adaptation: How cells respond to lysosomotropic compounds. PLoS One. 2017;12:e0173771. Available from: http://www.ncbi.n/m.nih.gov/pubmed/28301521.

66. Gavini J, Dommann N, Jakob MO, Keogh A, Bouchez LC, Karkampouna S, et al. Verteporfin-induced lysosomal compartment dysregulation potentiates the effect of sorafenib in hepatocellular carcinoma. Cell Death Dis. 2019;10: 749. Available from: http://www.nature.com/articles/s41419-019-1989-z.

\section{Publisher's Note}

Springer Nature remains neutral with regard to jurisdictional claims in published maps and institutional affiliations.

Ready to submit your research? Choose BMC and benefit from:

- fast, convenient online submission

- thorough peer review by experienced researchers in your field

- rapid publication on acceptance

- support for research data, including large and complex data types

- gold Open Access which fosters wider collaboration and increased citations

- maximum visibility for your research: over $100 \mathrm{M}$ website views per year

At $\mathrm{BMC}$, research is always in progress.

Learn more biomedcentral.com/submissions 